\title{
Article
}

\section{The Mutation Spectrum of Maturity Onset Diabetes of the Young (MODY)-Associated Genes among Western Siberia Patients}

\author{
Dinara E. Ivanoshchuk 1,2*(D), Elena V. Shakhtshneider ${ }^{1,2} \mathbb{D}$, Oksana D. Rymar $^{2}$, Alla K. Ovsyannikova ${ }^{2}$, \\ Svetlana V. Mikhailova ${ }^{1}$, Veniamin S. Fishman ${ }^{1}$, Emil S. Valeev ${ }^{1}$, Pavel S. Orlov ${ }^{1,2}$ and Mikhail I. Voevoda ${ }^{1}$ D \\ 1 Federal Research Center Institute of Cytology and Genetics, Siberian Branch of Russian Academy of \\ Sciences (SB RAS), Prospekt Lavrentyeva 10, 630090 Novosibirsk, Russia; \\ shakhtshneyderev@bionet.nsc.ru (E.V.S.); mikhail@bionet.nsc.ru (S.V.M.); minja@bionet.nsc.ru (V.S.F.); \\ emil@bionet.nsc.ru (E.S.V.); orlovpavel86@gmail.com (P.S.O.); mvoevoda@ya.ru (M.I.V.) \\ 2 Institute of Internal and Preventive Medicine-Branch of Institute of Cytology and Genetics, SB RAS, \\ Bogatkova Str. 175/1, 630004 Novosibirsk, Russia; orymar23@gmail.com (O.D.R.); \\ aknikolaeva@bk.ru (A.K.O.) \\ * Correspondence: dinara@bionet.nsc.ru or dinara2084@mail.ru; Tel.: +7-(383)-363-4963; Fax: +7-(383)-333-1278
}

Citation: Ivanoshchuk, D.E.; Shakhtshneider, E.V.; Rymar, O.D.; Ovsyannikova, A.K.; Mikhailova, S.V.; Fishman, V.S.; Valeev, E.S.; Orlov, P.S.; Voevoda, M.I. The Mutation Spectrum of Maturity Onset Diabetes of the Young (MODY)-Associated Genes among Western Siberia Patients. J. Pers. Med. 2021, 11, 57. https://doi.org/10.3390/jpm11010057

Received: 10 December 2020

Accepted: 13 January 2021

Published: 18 January 2021

Publisher's Note: MDPI stays neutral with regard to jurisdictional claims in published maps and institutional affiliations.

Copyright: (c) 2021 by the authors. Licensee MDPI, Basel, Switzerland. This article is an open access article distributed under the terms and conditions of the Creative Commons Attribution (CC BY) license (https:// creativecommons.org/licenses/by/ $4.0 /)$.
Abstract: Maturity onset diabetes of the young (MODY) is a congenital form of diabetes characterized by onset at a young age and a primary defect in pancreatic- $\beta$-cell function. Currently, 14 subtypes of MODY are known, and each is associated with mutations in a specific gene: $H N F 4 A, G C K$, HNF1A, PDX1, HNF1B, NEUROD1, KLF11, CEL, PAX4, INS, BLK, KCNJ11, ABCC8, and APPL1. The most common subtypes of MODY are associated with mutations in the genes GCK, HNF1A, $H N F 4 A$, and HNF1B. Among them, up to $70 \%$ of cases are caused by mutations in GCK and HNF1A. Here, an analysis of 14 MODY genes was performed in 178 patients with a MODY phenotype in Western Siberia. Multiplex ligation-dependent probe amplification analysis of DNA samples from 50 randomly selected patients without detectable mutations did not reveal large rearrangements in the MODY genes. In 38 patients ( $37 \%$ males) among the 178 subjects, mutations were identified in HNF4A, GCK, HNF1A, and ABCC8. We identified novel potentially causative mutations p.Lys142*, Leu146Val, Ala173Glnfs*30, Val181Asp, Gly261Ala, IVS7 c.864 -1G>T, Cys371*, and Glu443Lys in GCK and Ser6Arg, IVS 2 c.526 +1 G>T, IVS3 c.713 +2 T>A, and Arg238Lys in HNF1A.

Keywords: maturity onset diabetes of the young; MODY; diabetes mellitus; multiplex ligationdependent probe amplification; next-generation sequencing; GCK; HNF1A; HNF4A; HNF1B; singlenucleotide variant; population

\section{Introduction}

Maturity onset diabetes of the young (MODY) is a congenital form of diabetes characterized by onset at a young age and a primary defect in pancreatic- $\beta$-cell function. This type of diabetes (OMIM \# 606391) differs from classic types of diabetes mellitus (types 1 and 2, or T1DM and T2DM) in its clinical course, treatment strategies, and prognosis [1,2]. MODY is predominantly inherited in an autosomal dominant manner, but cases of spontaneous mutagenesis and germline mosaicism have been described [3,4]. MODY can be suspected [5] when hyperglycemia is detected in patients under 25-35 years of age, there is little or no need for insulin, secretion of $C$-peptide is intact, $\beta$-cell antibodies are absent, and dysfunction of pancreatic $\beta$-cells results in a decrease in the insulin amount. MODY patients usually have a normal body mass index. Currently, 14 subtypes of MODY are known, and each is associated with mutations in a specific gene: $H N F 4 A, G C K, H N F 1 A$, PDX1, HNF1B, NEUROD1, KLF11, CEL, PAX4, INS, BLK, KCNJ11, ABCC8, and APPL1 [6]. The genes associated with MODY are presented in Table 1. 
Table 1. The genes associated with maturity onset diabetes of the young (MODY).

\begin{tabular}{|c|c|c|c|}
\hline MODY Type & Gene & Protein Name & Genomic Location GRCh37 (hg19) \\
\hline MODY1 & $H N F 4 A$ & Hepatic Nuclear Factor 4 Alpha & chr20:42,984,340-43,061,485 \\
\hline MODY2 & GCK & Glucokinase (Hexokinase 4) & chr7:44,183,870-44,237,769 \\
\hline MODY3 & HNF1A & Hepatocyte Nuclear Factor 1-Alpha & chr12:121,416,346-121,440,315 \\
\hline MODY4 & PDX1 & Pancreatic and Duodenal Homeobox 1 & chr13:28,494,157-28,500,451 \\
\hline MODY5 & HNF1B & Hepatocyte Nuclear Factor 1-Beta & chr17:36,046,434-36,105,237 \\
\hline MODY6 & NEUROD1 & Neuronal Differentiation 1 & chr2:182,537,815-182,545,603 \\
\hline MODY7 & KLF11 & Krüppel-Like Factor 11 & chr2:10,182,976-10,194,963 \\
\hline MODY8 & $C E L$ & Carboxyl Ester Lipase & chr9:135,937,365-135,947,248 \\
\hline MODY9 & PAX4 & Paired Box 4 & chr7:127,250,346-127,255,982 \\
\hline MODY10 & INS & Insulin & chr11:2,181,009-2,182,571 \\
\hline MODY11 & $B L K$ & BLK Proto-Oncogene, Src Family Tyrosine Kinase & chr8:11,351,510-11,422,113 \\
\hline MODY12 & $A B C C 8$ & ATP-Binding Cassette Subfamily C Member 8 & chr11:17,414,432-17,498,449 \\
\hline MODY13 & KCNJ11 & $\begin{array}{l}\text { Potassium Inwardly Rectifying Channel Subfamily } \\
\text { J Member } 11\end{array}$ & chr11:17,406,795-17,410,878 \\
\hline MODY14 & APPL1 & $\begin{array}{l}\text { Adaptor Protein, Phosphotyrosine Interacting with } \\
\text { PH Domain and Leucine Zipper } 1\end{array}$ & chr3:57,261,765-57,307,499 \\
\hline
\end{tabular}

The most common subtypes of MODY are associated with mutations in the genes GCK, HNF1A, HNF4A, and HNF1B [7]; among them, up to 70\% of cases are caused by mutations in GCK and HNF1A [8]. Clinical manifestations of MODY are diverse and may vary even among members of the same family, i.e., carriers of identical mutations. This phenotypic variation is due to the interaction of the mutations with different genetic backgrounds and with environmental factors (e.g., the lifestyle) [9]. Identification of mutations causing MODY is important for early diagnosis of the disease in first-degree relatives of a proband. Up to $80 \%$ of MODY cases remain undetected or are misdiagnosed as T1DM or T2DM, resulting in incorrect treatment, including unjustified insulin therapy and its complications [1]. Next-generation sequencing (NGS) is most commonly used in MODY diagnostics and allows for simultaneous analysis of numerous genes and for the identification of single-nucleotide variants (SNVs) or small deletions or insertions, which constitute the majority of the known mutations causing this disease [10]. Nonetheless, large rearrangements in MODY-associated genes have been described, including heterozygosity of a complete $H N F 1 B$ deletion [11,12], detected by multiplex ligation-dependent probe amplification (MLPA). This method makes it possible to detect variations in the copy number of a gene and accordingly is widely used in molecular diagnostics of diseases whose pathogenesis is associated with deletions or duplications of certain genomic regions [13]. The purpose of the present study was to determine the spectrum of genetic variants in patients with a MODY phenotype in Russia (Western Siberia) by whole-exome sequencing, targeted sequencing, and MLPA.

\section{Materials and Methods}

\subsection{Patients}

The study protocol was approved by the Ethics Committee of the Institute of Internal and Preventive Medicine- branch of the Institute of Cytology and Genetics, SB RAS, Novosibirsk, Russia, protocol number 7, 22 June 2008. Written informed consent to be examined and to participate in the study was obtained from each patient or his/her parent or legal guardian.

A total of 178 unrelated patients aged 4 to 35 years $(23.4 \pm 11.1$ years [mean \pm SD]; $41.7 \%$ males) with a MODY phenotype and 140 available family members were enrolled in this study (Figure 1). 


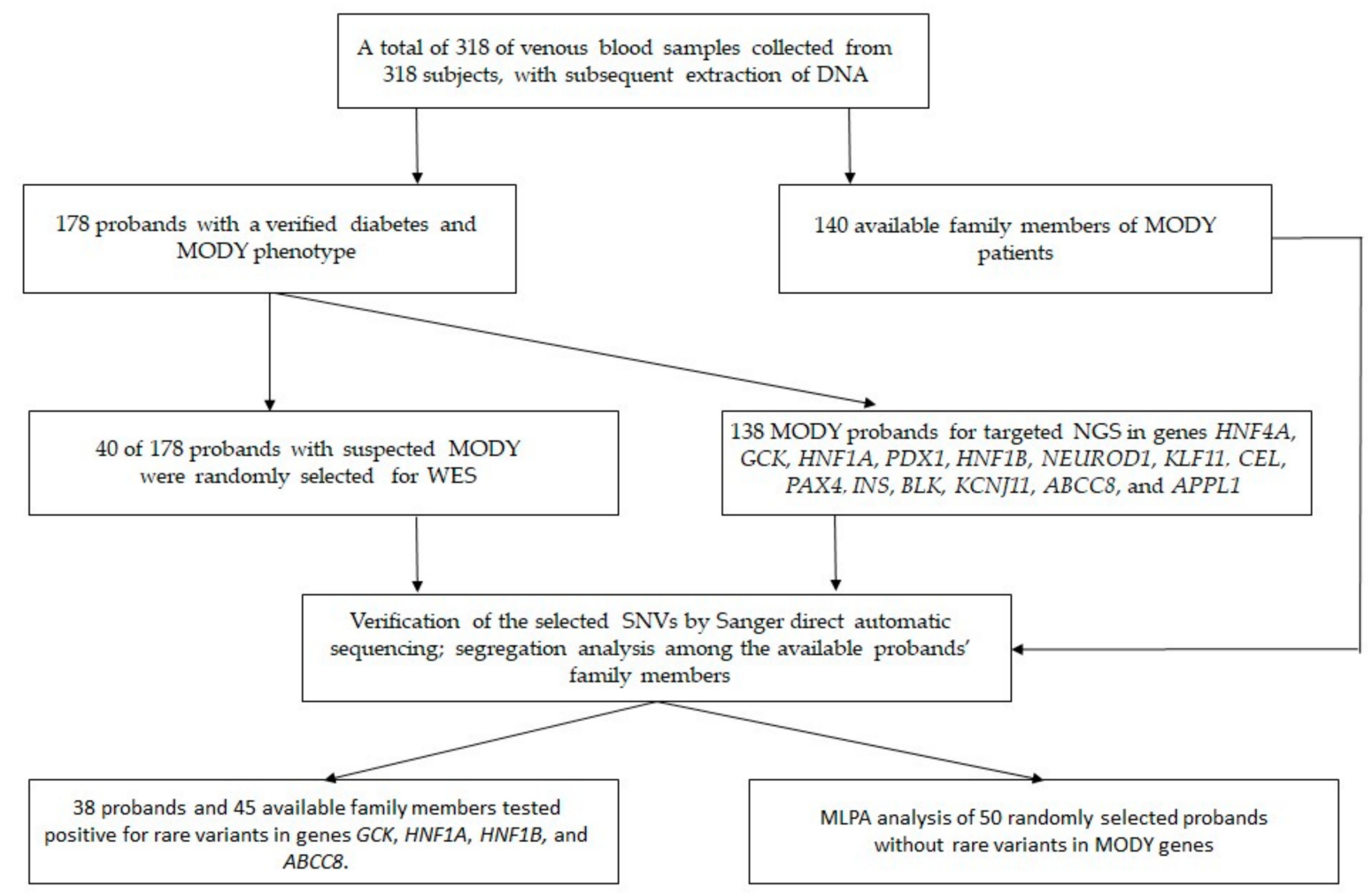

Figure 1. The study design. DNA: deoxyribonucleic acid, MLPA: multiplex ligation-dependent probe amplification, MODY: maturity onset diabetes of the young, SNV: single-nucleotide variant, WES: whole-exome sequencing.

All 178 probands were examined in the Clinical Department of the Institute of Internal and Preventive Medicine from the year 2014 to 2020. The probands were referred for molecular genetic testing if they met the following criteria: a verified diagnosis of diabetes [according to the criteria of the American Diabetes Association: $\mathrm{HbA} 1 \mathrm{C} \geq 6.5 \%$, or fasting plasma glucose $\geq 126 \mathrm{mg} / \mathrm{dL}(7.0 \mathrm{mmol} / \mathrm{L})$, or 2 -h plasma glucose $\geq 200 \mathrm{mg} / \mathrm{dL}$ $(11.1 \mathrm{mmol} / \mathrm{L})$ during an oral glucose tolerance test (in the absence of unequivocal hyperglycemia; the result should be confirmed by repeat testing), or a patient with classic symptoms of hyperglycemia or hyperglycemic crisis with a random plasma glucose $\geq 200 \mathrm{mg} / \mathrm{dL}(11.1 \mathrm{mmol} / \mathrm{L})$ ] [14]; a debut of the disease in probands at the age of 35 years or earlier; a family history of diabetes mellitus; the absence of obesity; the absence of antibodies against pancreas islet cells and glutamic acid decarboxylase; intact secretory function of $\beta$-cells; normal or mildly reduced C-peptide levels; no need for insulin therapy; and the absence of ketoacidosis at the onset of the disease. Patients with clinical features of untypical diabetes (differing from those of T1DM and T2DM) and, in some cases, lacking a family history were included in this study because MODY can be occasionally caused by de novo mutations [3,4]. Patients with a history of tuberculosis, infection with the human immunodeficiency virus, an infectious disease caused by hepatitis $B$ or $C$ virus that required antiviral treatment, or substance abuse or alcoholism in the 2 years before the examination were excluded from this study. The studied MODY group may have included patients with MODY, patients with T1DM and negative test results on antibodies, and patients with early-onset T2DM.

\subsection{Isolation of Genomic DNA}

Genomic DNA was isolated from venous blood leukocytes by phenol-chloroform extraction [15]. 


\subsection{Genome Library Preparation and Sequencing}

At the first stage, exome sequencing was performed on 40 randomly selected probands from the MODY group. The exome sequencing was carried out on an Illumina HiSeq 1500 instrument (Illumina, San Diego, CA, USA). The enrichment and library preparation were performed using the SureSelectXT Human All Exon v.5 + UTRs Kit. Whole-exome libraries were prepared with the AmpliSeq Exome Kit (Thermo Fisher Scientific, Walthamm, MA, USA). On the DNA samples from the other patients (138 unrelated probands), we performed targeted sequencing. In the target panel, we included coding parts and adjacent splicing sites of the following MODY-associated genes: HNF4A, GCK, HNF1A, PDX1, HNF1B, NEUROD1, KLF11, CEL, PAX4, INS, BLK, KCNJ11, ABCC8, and APPL1. Oligodeoxynucleotide probes and the KAPA HyperPlus Kit (Roche, Basel, Switzerland) were used to prepare libraries at the Genomics Multi-Access Center (Institute of Cytology and Genetics, SB RAS, Novosibirsk, Russia). The quality of the analyzed DNA and of the prepared libraries was evaluated by means of a capillary electrophoresis system, the Agilent 2100 Bioanalyzer (Agilent Technologies Inc., Santa Clara, CA, USA). Analysis of each fully prepared library was conducted on the Illumina MiSeq platform (Illumina, San Diego, CA, USA).

\subsection{Bioinformatic Analysis}

The sequence reads were mapped to the reference human genome (GRCh37/hg19) via the Burrow-Wheeler Alignment tool (BWA v.0.7.17) [16]. Polymerase chain reaction (PCR)-generated duplicates were removed with MarkDuplicates of PicardTools (https: //gatk.broadinstitute.org/hc/en-us). Base quality recalibration and searches for SNVs were conducted using Genome Analysis Toolkit (GATK) v.3.3, with BaseRecalibration and HaplotypeCaller tools, respectively; variant calling included local remapping of short insertions/deletions and correction of base quality [17].

The depth of coverage was $34 \times$ to $53 \times$. SNVs with genotype quality scores $<20$ were filtered out and excluded from further analysis. In sequenced groups, we kept sequence variants if they were present in 10 or more variant reads with a quality score $\geq 20$. Annotation of the SNVs was performed in the ANNOVAR (ANNOtate VARiation) software [18] with the help of populational data gnomAD [19] as a basic source and databases for several specific populations, such as The Greater Middle East (GME) Variome Project (http: //igm.ucsd.edu/gme/), ABraOM: Brazilian genomic variants (http://abraom.ib.usp.br/), Korean Personal Genome Project (http:/ / opengenome.net/Main_Page), other available data from populations and data on clinical significance (ClinVar) [20], and the Human Gene Mutation Database (HGMD) [10]; literature data were taken into account too.

Possible functional effects of SNVs were assessed in the dbNSFP database (https: //sites.google.com/site/jpopgen/dbNSFP), aggregating data from 37 in silico prediction tools (SIFT, Polyphen2, MutationTaster2, PROVEAN, and others), nine conservation scores (e.g., PhyloP, phastCons, GERP++, and SiPhy), and data on population frequencies. Thresholds for prediction scores were set according to respective authors' recommendations; for the conservation ratio, we set one single threshold at 0.7 , which means that a variant can be considered conserved if its predicted conservation score is greater than the scores of $70 \%$ variants.

Variants described in ClinVar, Leiden Open Variation Database (https: / /www.lovd. $\mathrm{nl} /$ ), or predicted in silico as benign (B) or likely benign (LB) as well as variants with minor allele frequency higher than $0.01 \%$ in any of the population databases listed above were excluded from the analysis. The pathogenicity of each novel candidate mutation was assessed according to the recommendations of the American College of Medical Genetics and Genomics (ACMG) and the Association for Molecular Pathology [21]. Using these criteria, we also assessed two variants (p.Val590Met in the HNF1A gene in proband P81 and p.Ala173Thr in the GCK gene in P90) previously reported without any description of a phenotype (Table 2). 
Table 2. The genetic variants identified in Western Siberia patients with a phenotype of maturity onset diabetes of the young (MODY).

\begin{tabular}{|c|c|c|c|c|c|c|c|c|c|c|c|c|c|}
\hline $\begin{array}{l}\text { Patient ID, } \\
\text { Gender }\end{array}$ & Gene & $\begin{array}{l}\text { Variant } \\
\text { Status }\end{array}$ & $\begin{array}{l}\text { Nucleotide } \\
\text { Changes * }\end{array}$ & $\begin{array}{l}\text { Amino Acid } \\
\text { Changes }\end{array}$ & Location & Genotype & $\begin{array}{l}\text { Minor Allele } \\
\text { Frequency } \\
\text { (gnomAD) }\end{array}$ & dbSNP ID & $\begin{array}{c}\text { ClinVar } \\
\text { Variation ID }\end{array}$ & HGMD & $\begin{array}{l}\text { Pathogenicity } \\
\text { According to ACMG } \\
\text { [21], Evidence }\end{array}$ & $\begin{array}{c}\text { LOVD } \\
\text { Database ID }\end{array}$ & $\begin{array}{c}\text { Segregation } \\
\text { with } \\
\text { Phenotype in } \\
\text { Family }\end{array}$ \\
\hline $\begin{array}{l}\text { P6, Female } \\
\text { P50, Male }\end{array}$ & GCK & Known & c. $106 \mathrm{C}>\mathrm{T}$ & p.Arg36Trp & Exon 2 & $\begin{array}{l}\text { Heterozygous } \\
\text { Heterozygous }\end{array}$ & 0.000014 & rs762263694 & 431973 & CM940823 & PR & GCK_000007 & $\begin{array}{l}\text { Yes } \\
\text { Yes }\end{array}$ \\
\hline P59, Female & GCK & Known & c. $110 \mathrm{~T}>\mathrm{C}$ & p.Met37Thr & Exon 2 & Heterozygous & NA & NA & NA & NA & PR & GCK_000100 & Yes \\
\hline P17, Female & GCK & Known & c. $130 \mathrm{G}>\mathrm{A}$ & p.Gly44Ser & Exon 2 & Heterozygous & $\mathrm{NA}$ & rs267601516 & 76898 & CM013265 & PR & GCK_000029 & Yes \\
\hline P74, Female & GCK & Known & c. $238 \mathrm{G}>\mathrm{A}$ & p.Gly80Ser & Exon 3 & Heterozygous & $\mathrm{NA}$ & rs1554335761 & 449415 & CM970630 & PR & NA & Yes \\
\hline P51, Male & GCK & Novel & c. $424 \mathrm{~A}>\mathrm{T}$ & p.Lys142* & Exon 4 & Heterozygous & NA & NA & NA & NA & $\begin{array}{l}\text { Pathogenic, PVS1, } \\
\text { PM2, PM1, PP1 }\end{array}$ & NA & Yes \\
\hline P4, Male & GCK & Novel & c. $436 \mathrm{C}>\mathrm{G}$ & p. Leu146Val & Exon 4 & Heterozygous & NA & NA & NA & NA & $\begin{array}{c}\text { Pathogenic, PS1, PS3, } \\
\text { PM2, PP1 } \\
\end{array}$ & NA & Yes \\
\hline P10, Male & GCK & Known & c. $449 \mathrm{~T}>\mathrm{A}$ & p. Phe150Tyr & Exon 4 & Heterozygous & NA & rs193922297 & 129142 & CM097114 & PR & $\mathrm{NA}$ & Yes \\
\hline P86, Female & GCK & Novel & c.517_520del & p.Ala173Glnfs*30 & Exon 5 & Heterozygous & NA & NA & NA & NA & $\begin{array}{c}\text { Pathogenic, PVS1, } \\
\text { PS1, PM2, PM4, PP1, } \\
\text { PP3 }\end{array}$ & NA & Yes \\
\hline P90, Male & GCK & Known & c. $517 \mathrm{G}>\mathrm{A}$ & p.Ala173Thr & Exon 5 & Heterozygous & NA & NA & NA & NA & $\begin{array}{c}\text { Pathogenic, PS1, PM2, } \\
\text { PM5, PP1, PP3 }\end{array}$ & GCK_000217 & Yes \\
\hline $\begin{array}{l}\text { P80, Female } \\
\text { P46, Female }\end{array}$ & GCK & Novel & c. $.542 \mathrm{~T}>\mathrm{A}$ & Val181Asp & Exon 5 & $\begin{array}{l}\text { Heterozygous } \\
\text { Heterozygous }\end{array}$ & NA & NA & NA & NA & $\begin{array}{c}\text { Pathogenic, PS1, PM2, } \\
\text { PM5, PP1, PP3 }\end{array}$ & NA & $\begin{array}{l}\text { Yes } \\
\text { Yes }\end{array}$ \\
\hline P30, Female & GCK & Known & c. $660 \mathrm{C}>\mathrm{A}$ & p.Cys220* & Exon 6 & Heterozygous & NA & NA & NA & CM020443 & PR & NA & Yes \\
\hline P68, Female & GCK & Known & c.700T $>C$ & p.Tyr234His & Exon 7 & Heterozygous & NA & NA & NA & CM096864 & PR & NA & Yes \\
\hline P40, Female & GCK & Known & c. $752 \mathrm{~T}>\mathrm{C}$ & p. Met251Thr & Exon 7 & Heterozygous & NA & rs193922326 & 36251 & CM096876 & PR & NA & Yes \\
\hline P67, Male & GCK & Known & c. $755 \mathrm{G}>\mathrm{A}$ & p.Cys252Tyr & Exon 7 & Heterozygous & NA & NA & NA & CM021266 & PR & NA & NA \\
\hline P83, Male & GCK & Known & c. $771 \mathrm{G}>\mathrm{A}$ & p.Trp257* & Exon7 & Heterozygous & $\mathrm{NA}$ & $\mathrm{NA}$ & NA & NA & Reported in [22] & $\mathrm{NA}$ & NA \\
\hline $\begin{array}{l}\text { P3, Male } \\
\text { P77, Female }\end{array}$ & GCK & Known & c. $772 \mathrm{G}>\mathrm{T}$ & p.Gly258Cys & Exon 7 & Heterozygous & NA & rs1583596378 & 804857 & CM032578 & PR & NA & $\begin{array}{l}\text { NA } \\
\text { Yes }\end{array}$ \\
\hline P88, Female & GCK & Novel & c. $782 \mathrm{G}>\mathrm{C}$ & p.Gly261Ala & Exon 7 & Heterozygous & NA & NA & NA & NA & $\begin{array}{c}\text { Pathogenic, PS1, PM2, } \\
\text { PM5, PP3 }\end{array}$ & NA & NA \\
\hline P54, Male & GCK & Novel & $c .864-1 \mathrm{G}>\mathrm{T}$ & - & Intron 7 & Heterozygous & NA & NA & NA & NA & $\begin{array}{l}\text { Pathogenic, PVS1, } \\
\text { PM2, PP1, PP3 }\end{array}$ & NA & Yes \\
\hline P57, Male & GCK & Novel & c. $1113 \mathrm{C}>\mathrm{A}$ & p.Cys371* & Exon 9 & Heterozygous & NA & NA & NA & NA & $\begin{array}{c}\text { Pathogenic, PVS1, } \\
\text { PS1, PM1, PM2, PM5, } \\
\text { PP1 }\end{array}$ & NA & Yes \\
\hline P70, Female & GCK & Known & c. $1120 \mathrm{G}>\mathrm{A}$ & p.Val374Met & Exon 9 & Heterozygous & NA & rs1415041911 & 447380 & CM096927 & PR & NA & Yes \\
\hline P61, Female & GCK & Known & c. $1148 \mathrm{C}>\mathrm{A}$ & p.Ser383* & Exon 9 & Heterozygous & 0.0000042 & rs777870079 & NA & CM032579 & PR & NA & Yes \\
\hline
\end{tabular}


Table 2. Cont.

\begin{tabular}{|c|c|c|c|c|c|c|c|c|c|c|c|c|c|}
\hline $\begin{array}{l}\text { Patient ID, } \\
\text { Gender }\end{array}$ & Gene & $\begin{array}{l}\text { Variant } \\
\text { Status }\end{array}$ & $\begin{array}{l}\text { Nucleotide } \\
\text { Changes* }\end{array}$ & $\begin{array}{l}\text { Amino Acid } \\
\text { Changes }\end{array}$ & Location & Genotype & $\begin{array}{l}\text { Minor Allele } \\
\text { Frequency } \\
\text { (gnomAD) }\end{array}$ & dbSNP ID & $\begin{array}{c}\text { ClinVar } \\
\text { Variation ID }\end{array}$ & HGMD & $\begin{array}{c}\text { Pathogenicity } \\
\text { According to ACMG } \\
\text { [21], Evidence }\end{array}$ & $\begin{array}{c}\text { LOVD } \\
\text { Database ID }\end{array}$ & $\begin{array}{c}\text { Segregation } \\
\text { with } \\
\text { Phenotype in } \\
\text { Family }\end{array}$ \\
\hline P87, Male & GCK & Novel & c.1327G $>\mathrm{A}$ & p.Glu443Lys & Exon 10 & Heterozygous & NA & NA & NA & NA & $\begin{array}{l}\text { Likely pathogenic, } \\
\text { PM1, PM2, PP2, PP3 }\end{array}$ & NA & NA \\
\hline P19, Female & HNF1A & Novel & c. $18 \mathrm{C}>\mathrm{G}$ & p.Ser6Arg & Exon 1 & Heterozygous & NA & NA & NA & NA & $\begin{array}{c}\text { Likely pathogenic, } \\
\text { PS4, PM2, PP1, PP2, } \\
\text { PP3 }\end{array}$ & NA & Yes \\
\hline P11, Female & HNF1A & Known & c. $185 \mathrm{~A}>\mathrm{G}$ & p.Asn62Ser & Exon 1 & Heterozygous & 0.00012 & rs377129682 & 447485 & CM064300 & PR & HNF1A_000235 & NA \\
\hline P34, Female & HNF1A & Novel & c. $526+1 \mathrm{G}>\mathrm{T}$ & - & Intron 2 & Heterozygous & NA & NA & NA & NA & $\begin{array}{l}\text { Pathogenic, PVS1, } \\
\text { PM2, PP1, PP2, PP3 }\end{array}$ & NA & Yes \\
\hline P65, Female & HNF1A & Known & c. $608 \mathrm{G}>\mathrm{A}$ & p.Arg203His & Exon 3 & Heterozygous & 0.000008 & rs587780357 & 129235 & CM993816 & PR & HNF1A_000137 & Yes \\
\hline P91, Female & HNF1A & Novel & c. $713 \mathrm{G}>\mathrm{A}$ & p.Arg238Lys & Exon 3 & Heterozygous & NA & NA & NA & NA & $\begin{array}{l}\text { Likely pathogenic, } \\
\text { PS1, PM2, PP2, PP3 }\end{array}$ & NA & NA \\
\hline P78, Male & HNF1A & Novel & c. $713+2 \mathrm{~T}>\mathrm{A}$ & - & Intron 3 & Heterozygous & NA & NA & NA & NA & $\begin{array}{l}\text { Pathogenic, PVS1, } \\
\text { PM2, PP1, PP2, PP3 }\end{array}$ & NA & Yes \\
\hline P82, Female & HNF1A & Known & c. $779 \mathrm{C}>\mathrm{T}$ & p.Thr260Met & Exon 4 & Heterozygous & 0.0000040 & rs886039544 & 265436 & CM971457 & PR & HNF1A_000148 & NA \\
\hline P16, Female & HNF1A & Known & c. $1522 \mathrm{G}>\mathrm{A}$ & p.Glu508Lys & Exon 6 & Heterozygous & 0.00044 & rs483353044 & 135665 & CM082841 & PR & HNF1A_000214 & NA \\
\hline P81, Male & HNF1A & Known & c. $1768 \mathrm{G}>\mathrm{A}$ & p.Val590Met & Exon 9 & Heterozygous & 0.0000042 & rs1168108747 & 447484 & NA & $\begin{array}{l}\text { Uncertain significance, } \\
\text { PM2, PP1, PP2, PP3 }\end{array}$ & NA & Yes \\
\hline P12, Male & $A B C C 8$ & Known & c. $4369 \mathrm{G}>\mathrm{C}$ & p.Ala1457Thr & Exon 36 & Heterozygous & NA & rs72559717 & NA & CM011260 & PR & NA & Yes \\
\hline P27, Female & HNF1B & Known & c. $1006 \mathrm{C}>\mathrm{G}$ & p.His336Asp & Exon 4 & Heterozygous & 0.0002 & rs138986885 & 595653 & CM067046 & PR & HNF1B_000125 & No \\
\hline
\end{tabular}

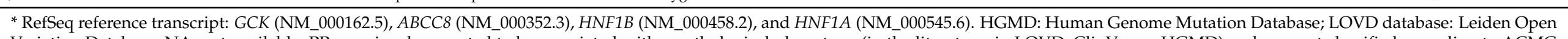

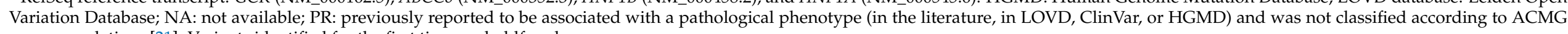
recommendations [21]. Variants identified for the first time are boldfaced. 
To identify pathogenic variants at potential splice sites, we performed in silico testing, using dbscSNV (http:/ / www.liulab.science/dbscsnv.html) for splice sites and regSNPintron (https: / / regsnps-intron.ccbb.iupui.edu/) for both intronic and splice-altering SNVs. Nevertheless, these databases can be only a supplementary tool for the estimation of variant pathogenicity, in addition to the population and clinical data.

\subsection{Verification Analysis}

All selected SNVs were verified by Sanger direct automatic sequencing on an ABI 3500 DNA sequencer (Thermo Fisher Scientific, USA) by means of the BigDye Terminator v3.1 Cycle Sequencing Kit (Thermo Fisher Scientific, USA). Primer design for the selected SNVs was performed in the Primer-Blast software (https://www.ncbi.nlm.nih.gov/tools/ primer-blast/).

At the second stage, segregation analysis was performed on the selected variants (novel and previously described) in the probands' family members available for the analysis.

\subsection{MLPA Analysis}

The third stage included an MLPA analysis of DNA samples from 50 randomly selected patients without detectable mutations in MODY-associated genes to search for major structural rearrangements (deletions and duplications). MLPA was performed using SALSA MLPA Probemix P241 MODY Mix 1 (MRC-Holland, Amsterdam, Netherlands), containing 52 specific MLPA probes for four genes: HNF4A, GCK, HNF1A, and HNF1B (https://www.mrcholland.com/product/P241/2528). The reaction was carried out in accordance with the manufacturer's recommendations. The resulting amplification products were detected by capillary electrophoresis on an ABI 3500 DNA sequencer (Thermo Fisher Scientific, USA). The data were processed in the Coffalyser.Net software.

\section{Results}

In 40 probands with a MODY phenotype, whole-exome analysis was performed; in 138 probands, we analyzed exons and adjacent splice sites of MODY-associated genes: HNF4A, GCK, HNF1A, PDX1, HNF1B, NEUROD1, KLF11, CEL, PAX4, INS, BLK, KCNJ11, $A B C C 8$, and APPL1. In this work, we ignored common genetic variants and did not assess their possible effects on the phenotype. The results are presented in Table 2. We did not find any rare pathogenic variants in genes HNF4A, PDX1, NEUROD1, KLF11, CEL, PAX4, INS, $B L K, K C N J 11$, and APPL1. In 38 patients ( $37 \%$ males) out of the 178 subjects, mutations were identified in HNF4A, GCK, HNF1A, and $A B C C 8$ (one in a compound heterozygous state and 37 in a heterozygous state). The vast majority of them were carriers of rare variants of the GCK gene (26 probands; $68.4 \%$ ), and nine probands (26.3\%) had mutations in the $H N F 1 A$ gene; one male $(2.6 \%)$ carried a pathogenic variant in the $A B C C 8$ gene, and one female was a carrier of a rare variant in HNF1B. One male patient (P73) was a compound heterozygote on two previously described mutations: Arg54* in HNF1A and Arg521Gln in $A B C C 8$.

In total, we identified 36 rare variants in the studied genes: 12 of them $(33.3 \%)$ are described for the first time, and the rest are present in databases (LOVD, HGMD, ClinVar, and/or gnomAD) or are previously reported in the literature. Among the identified variants, only three (all located in the GCK gene) were found twice in unrelated patients. Probands P3 and P77 both were found to carry Gly258Cys, probands P46 and P80 to carry undescribed Val181Asp, and probands P6 and P50 to carry Arg36Trp in the GCK gene. All the novel variants proved to be likely pathogenic or pathogenic according to the ACMG criteria [21]. For 28 families with identified relevant variants, a segregation analysis was performed. For most patients, segregation of the identified mutations with pathogenic phenotypes was found among their relatives.

An exception was the His336Asp mutation in HNF1B in a patient (P27) with gestational diabetes. The same mutation was found in her normoglycemic mother and her daughter. 
In 50 patients without mutations in the studied genes, the MLPA analysis did not reveal any structural abnormalities in the genes HNF4A, GCK, HNF1A, and HNF1B.

\section{Discussion}

Genetic diagnosis is an important step in clinical practice, especially for family screening of individuals with borderline or moderate carbohydrate metabolic disorders. Clinical manifestations of MODY differ among patients and do not allow us to identify the type of diabetes unambiguously; therefore, it is important to employ timely genetic diagnostics for the optimal choice of a treatment. In the present study, we searched for mutations in MODY-associated genes by combining an examination of clinical criteria with NGS (the latter method has been effectively used as a first-line screening test for MODY-associated mutations). Next, the identified mutations were verified by Sanger sequencing followed by cascade genetic screening of available family members. In a Siberian population, we have previously reported some of the mutations: c.580 -1G>A in GCK [23], Ser6Arg in HNF1A [24], and Ala1457Thr in ABCC8 [25]. Among the studied patients (all from Western Siberia), the predominance of subtypes MODY2 (68.4\%) and MODY3 (26.3\%) was demonstrated here. We found eight novel genetic variants in GCK and four novel variants in HNF1A in this work (Figure 2, Table 2).

Routine or accidental blood glucose testing is the main route of hyperglycemia detection in GCK-MODY. The disease is characterized by an insignificant increase in the fasting glucose level (well controlled without medication) and low prevalence of microand macrovascular complications of diabetes [2]. Encoded by the GCK gene, glucokinase B $(\mathrm{GlkB}$, hexokinase IV) is the first enzyme in the glycolytic pathway and phosphorylates glucose in pancreatic $\beta$-cells [26].
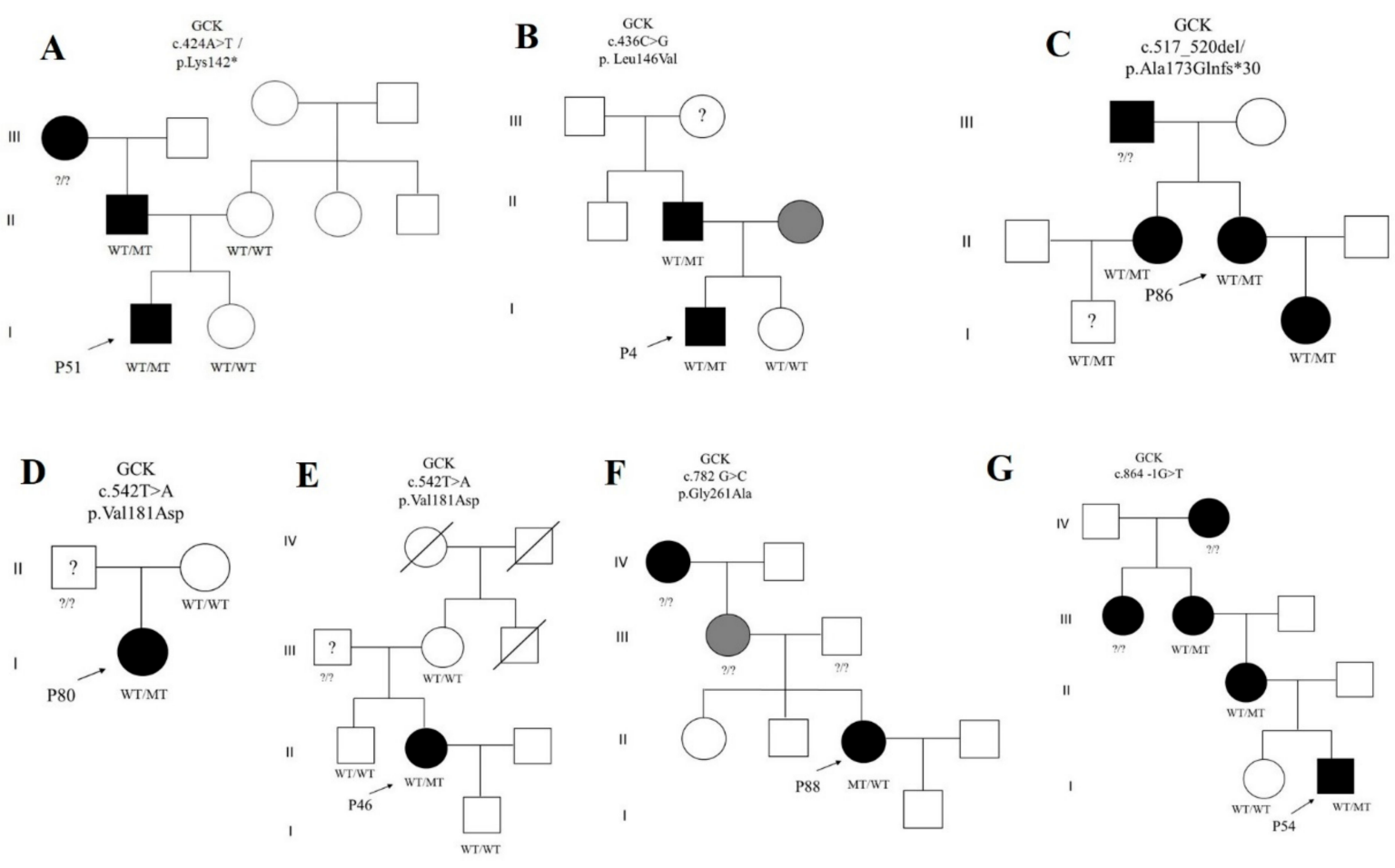

Figure 2. Cont. 


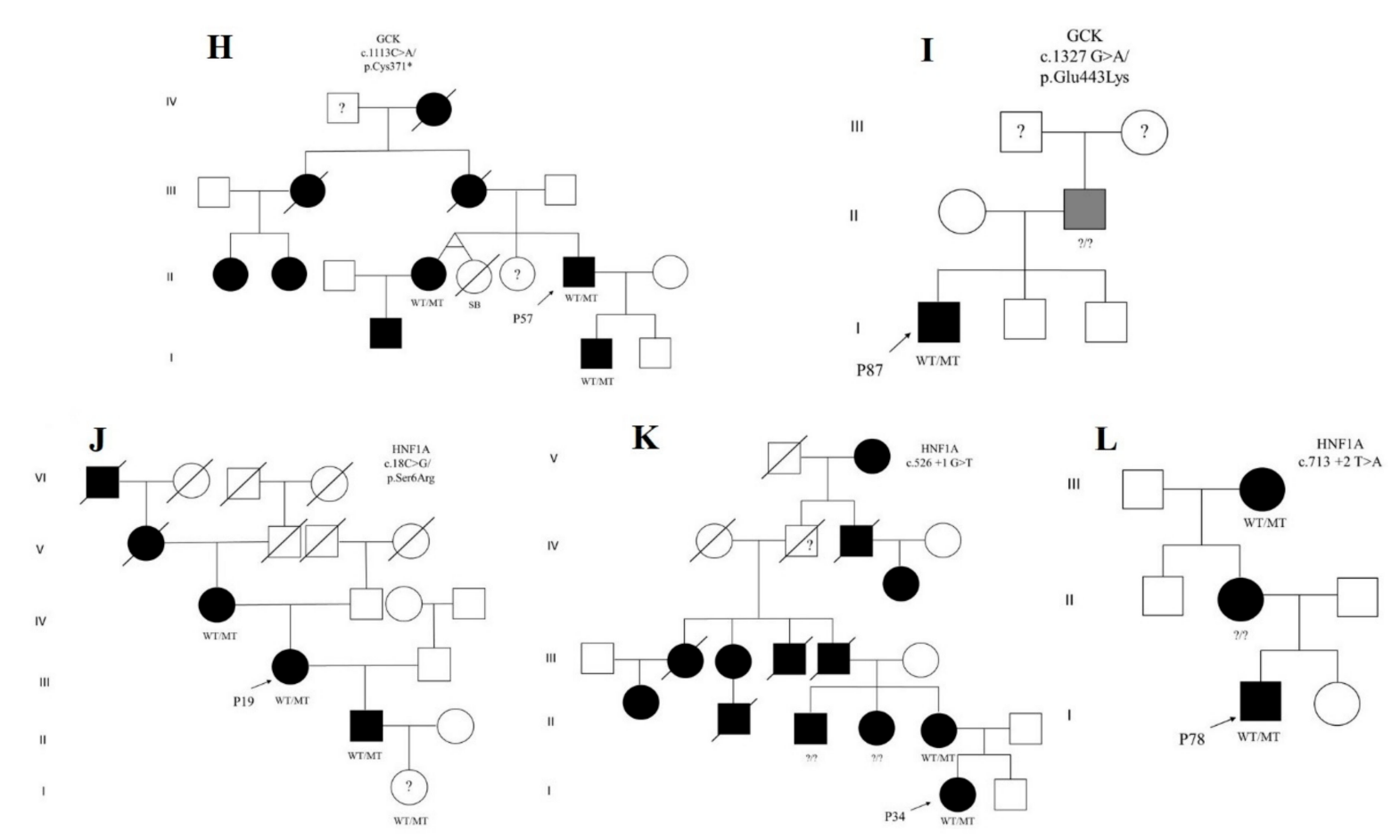

Figure 2. Screened MODY families (A-L) with novel identified variants in genes GCK and HNF1A. A grey filled symbol: a patient with prediabetes, MT: altered allele, SB: stillbirth, WT: wild type allele, ?/?: persons not genotyped, ?: a person with unknown health status. * RefSeq reference transcript: GCK (NM_000162.5), ABCC8 (NM_000352.3), HNF1B (NM_000458.2), and HNF1A (NM_000545.6).

The crystal structure of human glucokinase indicates that it has a large domain and small domain forming a deep cleft for glucose binding [27]. Amino acid residues 1-64 and 206-439 belong to the large domain, and residues 72-201 and 445-465 belong to the small domain; residues 65-71, 202-205, and 440-444 constitute three loops connecting the domains. Glucokinase is switched from an inactive to active conformation by ligand binding via a large rotation of the small domain $[27,28]$. Many mutations of this gene have been described (nonsense, missense, frameshift, and splice site mutations) in various populations [10]. Of note, all GCK-MODY patients have similar clinical phenotypes regardless of the mutation type [29].

p.Lys142* was found here in a 10-year-old boy (P51 in family A) with hyperglycemia. Lysine at codon 142 is adjacent to three basic amino acid residues (His-141, Lys-142, and Lys-143) that are phylogenetically conserved and form a positively charged surface. This basic patch in GlkB is believed to be a critical site for the binding of glucokinase-regulatory protein because substitutions at this site decrease this binding and nuclear entry of GlkB [30]. There are no reports on mutations in this codon in the literature.

The Leu146Val substitution is located in the small domain and was found in a 12-yearold male proband here (P4 in family B). Within codon 146, two other variants (Leu146Pro and Leu146Arg) have been described, both associated with MODY [10]. Research on enzyme kinetics has revealed that mutation Leu146Arg reduces enzymatic activity owing to decreased affinity for glucose [31].

A novel frameshift mutation, p.Ala173Glnfs*30, was identified here in family $C$ with a MODY2 phenotype. Namely, this heterozygous deletion of four nucleotides in exon 5 was detected in a young woman 35 years of age (P86), in her son, and in her sibling. This AGGC deletion in codon 173 of the GCK gene changes the amino acid sequence and generates a premature stop codon at amino acid position 203. In our study, this variant segregated with the pathological phenotype in the proband and proband's daughter and sister. In view of the young age of the proband's nephew, monitoring of his carbohydrate metabolism 
parameters was recommended. Enzyme kinetics should be assessed to determine the functional basis of the disease.

In two unrelated female patients (P80 in family D and P46 in family E), a variant was found resulting in the replacement of valine in codon 181 with aspartic acid. In both families, the supposed carriers (fathers) of the Val181Ala variant were not available for the analysis; it turned out that healthy mothers of the probands and relatives of P46 are not carriers of this substitution. Val181Ala in a family of a MODY patient was described in Italy [32]. In the present study, a young patient (P88 in family F) with gestational diabetes mellitus and a family history of diabetes was found to have a previously undescribed missense substitution, Gly261Ala, in the GCK gene. Earlier, two substitution variants of this codon-Gly261Arg and Gly261Glu-were found in France [33,34], both associated with MODY.

Here, in a 2-year-old boy (P54 in family G) with hyperglycemia, the c.864 -1G>T substitution was identified in the acceptor site of GCK intron 7. This variant segregated with a pathological phenotype in the examined family members. Substitutions $-1 G>A$ and $-1 G>C$ at this position have been described in the United Kingdom and Czech Republic [35,36].

Several variants in codon Cys371 have been described [10]. We first identified a nonsense variant in this codon in patient P57 (family H). The substitution segregated with a pathological phenotype in other family members. Cys371 is a highly conserved amino acid residue located in the hydrophobic core of the protein [37], where it participates in disulfide bond formation [38].

It is known that L-arginine stimulates the production of glucose-6-phosphate and induces insulin secretion [39]. In a male patient (P87) in family I, the p.Glu443Lys variant was detected, which is involved in L-arginine binding and insulin secretion [39]. Glu443 is located in the $\alpha-13$ helix of human GlkB [26]. During the domain reorganization between the active and inactive forms of the enzyme, helices $\alpha-13$ and $\alpha-5$ take part in the global conformational change [27].

Hepatocyte nuclear factor I homeobox A (HNF1A) is a transcription factor regulating the differentiation of pancreatic cells [40]. Mutations in the HNF1A gene are associated with MODY3, which is characterized by impaired insulin secretion, retention of sensitivity to sulfonylureas, and a decrease in the renal threshold for glucose. Cases of liver adenomatosis, renal dysplasia, and hypopituitarism in carriers of these mutations have been documented $[41,42]$. The clinical manifestations of MODY3 can vary within the same family and among unrelated mutation carriers. Moreover, carriers of HNF1A gene mutations may be normoglycemic, while their siblings can be hyperglycemic [43].

The Ser6Arg mutation of the HNF1A gene was found here in a family with diabetes mellitus in five generations [24] in proband P19 (family J). Another variant, c.526 +1 G>T in intron 2 of HNF1A, was detected in a 12-year-old patient (proband P34 in family K). She was found to have fasting hyperglycemia of $11.3 \mathrm{mmol} / \mathrm{L}$ and glycosuria of more than $55 \mathrm{mmol} / \mathrm{L}$. In the proband's family, this variant segregated with a pathological phenotype and has not been described previously.

Proband P91 is a carrier of novel variant Arg238Lys. Two other substitutions at the same position, Arg238Met and Arg238Thr, have been previously described in the LOVD database as likely pathogenic (HNF1A_000306 and HNF1A_000417). One of them, Arg238Thr, is associated with MODY in the United Kingdom [44], and the other one, Arg238Met, is associated with hyperinsulinism diagnosed at birth (LOVD database). According to the proband, her ancestors had diabetes mellitus for three generations, but they were not available for analysis.

One of our young male patients (P78 in family L) has substitution c.713 +2 T>A in intron 3 of the HNF1A gene. In an available relative of the proband, this mutation segregated with non-insulin-dependent diabetes mellitus and was found for the first time.

ATP-binding cassette superfamily transporter family $\mathrm{C} 8$ gene $(A B C C 8)$ encodes sulfonylurea receptor 1 (SUR1), which is a part of ATP-sensitive potassium channels on the 
islet $\beta$-cell membrane. Mutations in this gene can cause T2DM [45], a transient type of neonatal diabetes [46], neonatal diabetes [47], or MODY12 [6]. Previously, for the first time in Russia, we described the case of a patient with an $A B C C 8$ mutation [25]. In the current study, a 13-year-old male patient (P73, family history is not shown) proved to be compound heterozygous on Arg521Gln of $A B C C 8$ and previously reported Arg54* of HNF1A. His mother, also with diabetes mellitus, has the same genotype. Elsewhere, the Arg521Gln substitution in the ABCC8 protein has been identified in a female with dominant hyperinsulinism [48] and in a case of a heterozygous carrier with diabetes [49]. In our case, neither the mother nor her son had any relevant complications.

A mutation in the HNF1B gene results in MODY5, which is characterized by reduced insulin secretion and usually a renal disease [50]. This gene plays the major part in the normal development of (and tissue-specific gene expression in) the kidneys, liver, pancreas, bile ducts, urogenital tract, lungs, thymus, and gut [50]. In patient P27 (family history is not shown), a diagnosis of gestational diabetes was made. Mutation His336Asp in HNF1B was detected in a proband and in her normoglycemic mother and daughter; no other HNF1Bassociated clinical phenotypes, such as genital deformities or kidney involvement, were revealed in this proband [51]. The information on the pathogenicity of this variant is unclear. This mutation has been identified and categorized as pathogenic in two unrelated patients with severe renal anomalies, but healthy relatives of the patients are reported to be carriers of the mutation as well [52]. In another study, two out of three affected members from one family were carriers of this mutation, and it was found in one healthy individual [53]. In other studies, this variant was identified in a patient with suspected T1DM and absence of autoimmunity, but information about their parents was not available [54]. It is likely that the mutation does not have $100 \%$ penetrance and that other modulating pathological factors, including genetic ones, are required for disease manifestation.

In Russia, genetic screening of patients with MODY has been previously performed in the European part of Russia, and mutations in the GCK gene seem to be most prevalent among these MODY patients $[55,56]$.

Direct sequencing of MODY genes is time-consuming and does not cover the entire spectrum of genes that can cause this type of diabetes. NGS techniques enable more efficient and cost-effective diagnosis of MODY subtypes [57]. High-tech sequencing also helps to determine the cause of a MODY phenotype if mutations in the genes known to be associated with MODY1-MODY14 are absent.

\section{Limitations}

This study has some limitations due to the unavailability of information about probands' family members (in some cases). This situation did not allow us to perform a segregation analysis of some rare potentially pathogenic variants identified in our patients (data not shown).

\section{Conclusions}

The spectrum of mutations in MODY genes was determined in a Western Siberian population by NGS. We believe that NGS techniques will lead to more effective and cost-efficient methods of MODY diagnosis. Apparently, mutations in the GCK gene are the predominant cause of MODY in Russia. We identified novel potentially causative mutations p.Lys142*, Leu146Val, Ala173Glnfs*30, Val181Asp, Gly261Ala, IVS7 c.864 -1G>T, Cys371*, and Glu443Lys in GCK and Ser6Arg, IVS 2 c.526 +1 G>T, IVS3 c.713 +2 T>A, and Arg238Lys in HNF1A (both are known MODY-associated genes). We did not find large rearrangements in MODY genes in a randomly selected cohort of 50 patients devoid of relevant point mutations.

Author Contributions: Conceptualization, M.I.V.; data curation, E.V.S., O.D.R., and A.K.O.; investigation, D.E.I.; methodology, D.E.I., E.S.V., and V.S.F.; project administration, M.I.V.; validation, S.V.M. and P.S.O.; writing-Original draft, D.E.I., E.V.S., E.S.V., and V.S.F.; writing-Review and editing, E.V.S. and S.V.M. All authors have read and agreed to the published version of the manuscript. 
Funding: The collection of the samples and of clinical data and clinical examination were conducted as part of the main topic in state assignment No. AAAA-A17-117112850280-2, and NGS, Sanger sequencing, and bioinformatic analyses are financially supported as part of the publicly funded topic in state assignment No. AAAA-A19-119100990053-4.

Institutional Review Board Statement: The study protocol was approved by the Ethics Committee of the Institute of Internal and Preventive Medicine-Branch of the Institute of Cytology and Genetics, SB RAS, Novosibirsk, Russia, protocol number 7, 22 June 2008.

Informed Consent Statement: Informed consent was obtained from all subjects or his/her parent or legal guardian involved in the study.

Data Availability Statement: The data presented in this study are available on request from the corresponding author. The data are not publicly available due to privacy.

Acknowledgments: The authors thank the patients for the participation in this study.

Conflicts of Interest: The authors declare that they have no conflicts of interest related to the publication of this article.

\section{References}

1. Steele, A.M.; Shields, B.M.; Wensley, K.J.; Colclough, K.; Ellard, S.; Hattersley, A.T. Prevalence of vascular complications among patients with glucokinase mutations and prolonged, mild hyperglycemia. JAMA 2014, 311, 279-286. [CrossRef] [PubMed]

2. Murphy, R.; Ellard, S.; Hattersley, A.T. Clinical implication of a molecular genetic classification of monogenic $\beta$-cell diabetes. Nat. Clin. Pract. Endocrinol. Metab. 2008, 4, 200-213. [CrossRef]

3. Stanik, J.; Dusatkova, P.; Cinek, O.; Valentinova, L.; Huckova, M.; Skopkova, M.; Dusatkova, L.; Stanikova, D.; Pura, M.; Klimes, I.; et al. De novo mutations of GCK, HNF1A and HNF4A may be more frequent in MODY than previously assumed. Diabetologia 2014, 57, 480-484. [CrossRef] [PubMed]

4. Yorifuji, T.; Kurokawa, K.; Mamada, M.; Imai, T.; Kawai, M.; Nishi, Y.; Shishido, S.; Hasegawa, Y.; Nakahata, T. Neonatal diabetes mellitus and neonatal polycystic, dysplastic kidneys: Phenotypically discordant recurrence of a mutation in the hepatocyte nuclear factor-1beta gene due to germline mosaicism. J. Clin. Endocrinol. Metab. 2004, 89, 2905-2908. [CrossRef] [PubMed]

5. Shields, B.M.; McDonald, T.J.; Ellard, S.; Campbell, M.J.; Hyde, C.; Hattersley, A.T. The development and validation of a clinical prediction model to determine the probability of MODY in patients with young-onset diabetes. Diabetologia 2012, 55, 1265-1272. [CrossRef] [PubMed]

6. Firdous, P.; Nissar, K.; Ali, S.; Ganai, B.A.; Shabir, U.; Hassan, T.; Masoodi, S.R. Genetic Testing of Maturity-Onset Diabetes of the Young Current Status and Future Perspectives. Front. Endocrinol. 2018, 9, 253. [CrossRef]

7. Shields, B.M.; Hicks, S.; Shepherd, M.H.; Colclough, K.; Hattersley, A.T.; Ellard, S. Maturity-onset diabetes of the young (MODY): How many cases are we missing? Diabetologia 2010, 53, 2504-2508. [CrossRef]

8. Ellard, S.; Bellanné-Chantelot, C.; Hattersley, A.T. European Molecular Genetics Quality Network (EMQN) MODY group. Best practice guidelines for the molecular genetic diagnosis of maturity-onset diabetes of the young. Diabetologia 2008, 51, 546-553. [CrossRef]

9. Fajans, S.S.; Bell, G.I. MODY: History, genetics, pathophysiology, and clinical decision making. Diabetes Care 2011, 34, 1878-1884. [CrossRef]

10. Stenson, P.D.; Ball, E.V.; Mort, M.; Phillips, A.D.; Shiel, J.A.; Thomas, N.S.T.; Abeysinghe, S.; Krawczak, M.; Cooper, D.N. Human Gene Mutation Database (HGMD): 2003 update. Hum. Mutat. 2003, 21, 577-581. [CrossRef]

11. Dotto, R.P.; Mathez, A.L.G.; Franco, L.F.; de Sá, J.R.; Weinert, L.S.; Silveiro, S.P.; de Mello Almada Giuffrida, F.; da Silva, M.R.D.; Reis, A.F. Improving the identification of mody mutations by using MLPA technique in the molecular diagnostics routine. Diabetol. Metab. Syndr. 2015, 11, A246. [CrossRef]

12. Tatsi, E.B.; Kanaka-Gantenbein, C.; Scorilas, A.; Chrousos, G.P.; Sertedaki, A. Next generation sequencing targeted gene panel in Greek MODY patients increases diagnostic accuracy. Pediatr. Diabetes 2020, 21, 28-39. [CrossRef] [PubMed]

13. Stuppia, L.; Antonucci, I.; Palka, G.; Gatta, V. Use of the MLPA assay in the molecular diagnosis of gene copy number alterations in human genetic diseases. Int. J. Mol. Sci. 2012, 13, 3245-3276. [CrossRef] [PubMed]

14. American Diabetes Association. Standards of medical care in diabetes-2013. Diabetes Care 2013, 36, 11-66. [CrossRef] [PubMed]

15. Sambrook, J.; Russell, D.W. Purification of nucleic acids by extraction with phenol: Chloroform. Cold Spring Harb. Protoc. 2006, 2006, 4455. [CrossRef]

16. Li, H.; Durbin, R. Fast and accurate short read alignment with Burrows-Wheeler transform. Bioinformatics 2009, 25, 1754-1760. [CrossRef]

17. McKenna, A.; Hanna, M.; Banks, E.; Sivachenko, A.; Cibulskis, K.; Kernytsky, A.; Garimella, K.; Altshuler, D.; Gabriel, S.; Daly, M.; et al. The Genome Analysis Toolkit: A MapReduce framework for analyzing next-generation DNA sequencing data. Genome Res. 2010, 20, 1297-1303. [CrossRef] 
18. Wang, K.; Li, M.; Hakonarson, H. ANNOVAR: Functional annotation of genetic variants from next-generation sequencing data. Nucleic Acids Res 2010, 38, e164. [CrossRef]

19. Karczewski, K.J.; Francioli, L.C.; Tiao, G.; Cummings, B.B.; Alföldi, J.; Wang, Q.; Collins, R.L.; Laricchia, K.M.; Ganna, A.; Birnbaum, D.P.; et al. The mutational constraint spectrum quantified from variation in 141,456 humans. Nature 2020, 581, $434-443$. [CrossRef]

20. Landrum, M.J.; Lee, J.M.; Benson, M.; Brown, G.R.; Chao, C.; Chitipiralla, S.; Gu, B.; Hart, J.; Hoffman, D.; Jang, W.; et al. ClinVar: Improving access to variant interpretations and supporting evidence. Nucleic Acids Res. 2018, 46, D1062-D1067. [CrossRef]

21. Richards, S.; Aziz, N.; Bale, S.; Bick, D.; Das, S.; Gastier-Foster, J.; Grody, W.W.; Hegde, M.; Lyon, E.; Spector, E.; et al. Standards and guidelines for the interpretation of sequence variants: A joint consensus recommendation of the American College of Medical Genetics and Genomics and the Association for Molecular Pathology. Genet. Med. 2015, 17, 405-423. [CrossRef] [PubMed]

22. Wang, Z.; Diao, C.; Liu, Y.; Li, M.; Zheng, J.; Zhang, Q.; Yu, M.; Zhang, H.; Ping, F.; Li, M.; et al. Identification and functional analysis of GCK gene mutations in 12 Chinese families with hyperglycemia. J. Diabetes Investig. 2019, 10, 963-971. [CrossRef] [PubMed]

23. Ivanoshchuk, D.E.; Shakhtshneider, E.V.; Ovsyannikova, A.K.; Mikhailova, S.V.; Rymar, O.D.; Oblaukhova, V.I.; Yurchenko, A.A.; Voevoda, M.I. A rare splice site mutation in the gene encoding glucokinase/hexokinase 4 in a patient with MODY type 2. Vavilov J. Genet. Breed. 2020, 24, 299-305. [CrossRef]

24. Ovsyannikova, A.K.; Rymar, O.D.; Ivanoshchuk, D.E.; Mikhailova, S.V.; Shakhtshneider, E.V.; Orlov, P.S.; Malakhina, E.S.; Voevoda, M.I. A Case of Maturity Onset Diabetes of the Young (MODY3) in a Family with a Novel HNF1A Gene Mutation in Five Generations. Diabetes Ther. 2018, 9, 413-420. [CrossRef] [PubMed]

25. Ovsyannikova, A.K.; Rymar, O.D.; Shakhtshneider, E.V.; Klimontov, V.V.; Koroleva, E.A.; Myakina, N.E.; Voevoda, M.I. ABCC8Related Maturity-Onset Diabetes of the Young (MODY12): Clinical Features and Treatment Perspective. Diabetes Ther. 2016, 7, 591-600. [CrossRef]

26. Pedelini, L.; Garcia-Gimeno, M.A.; Marina, A.; Gomez-Zumaquero, J.M.; Rodriguez-Bada, P.; López-Enriquez, S.; Soriguer, F.C.; Cuesta-Muñoz, A.L.; Sanz, P. Structure-function analysis of the alpha5 and the alpha13 helices of human glucokinase: Description of two novel activating mutations. Protein Sci. 2005, 14, 2080-2086. [CrossRef]

27. Kamata, K.; Mitsuya, M.; Nishimura, T.; Eiki, J.; Nagata, Y. Structural basis for allosteric regulation of the monomeric allosteric enzyme human glucokinase. Structure 2004, 12, 429-438. [CrossRef]

28. Capuano, M.; Garcia-Herrero, C.M.; Tinto, N.; Carluccio, C.; Capobianco, V.; Coto, I.; Cola, A.; Iafusco, D.; Franzese, A.; Zagari, A.; et al. Glucokinase (GCK) mutations and their characterization in MODY2 children of southern Italy. PLoS ONE 2012, 7, e38906. [CrossRef]

29. Stride, A.; Vaxillaire, M.; Tuomi, T.; Barbetti, F.; Njølstad, P.R.; Hansen, T.; Costa, A.; Conget, I.; Pedersen, O.; Søvik, O.; et al. The genetic abnormality in the beta cell determines the response to an oral glucose load. Diabetologia 2002, 45, 427-435. [CrossRef]

30. Fenner, D.; Odili, S.; Hong, H.K.; Kobayashi, Y.; Kohsaka, A.; Siepka, S.M.; Vitaterna, M.H.; Chen, P.; Zelent, B.; Grimsby, J.; et al. Generation of N-ethyl-N-nitrosourea (ENU) diabetes models in mice demonstrates genotype-specific action of glucokinase activators. J. Biol. Chem. 2011, 286, 39560-39572. [CrossRef]

31. Sagen, J.V.; Odili, S.; Bjørkhaug, L.; Zelent, D.; Buettger, C.; Kwagh, J.; Stanley, C.; Dahl-Jørgensen, K.; de Beaufort, C.; Bell, G.I. From clinicogenetic studies of maturity-onset diabetes of the young to unraveling complex mechanisms of glucokinase regulation. Diabetes 2006, 55, 1713-1722. [CrossRef] [PubMed]

32. Massa, O.; Meschi, F.; Cuesta-Munoz, A.; Caumo, A.; Cerutti, F.; Toni, S.; Cherubini, V.; Guazzarotti, L.; Sulli, N.; Matschinsky, F.M.; et al. High prevalence of glucokinase mutations in Italian children with MODY. Influence on glucose tolerance, first-phase insulin response, insulin sensitivity and BMI. Diabetologia 2001, 44, 898-905. [CrossRef] [PubMed]

33. Hager, J.; Blanché, H.; Sun, F.; Vaxillaire, N.V.; Poller, W.; Cohen, D.; Czernichow, P.; Velho, G.; Robert, J.J.; Cohen, N.; et al. Six mutations in the glucokinase gene identified in MODY by using a nonradioactive sensitive screening technique. Diabetes 1994, 43, 730-733. [CrossRef]

34. Stoffel, M.; Froguel, P.; Takeda, J.; Zouali, H.; Vionnet, N.; Nishi, S.; Weber, I.T.; Harrison, R.W.; Pilkis, S.J.; Lesage, S.; et al. Human glucokinase gene: Isolation, characterization, and identification of two missense mutations linked to early-onset non-insulin-dependent (type 2) diabetes mellitus. Proc. Natl. Acad. Sci. USA 1992, 89, 7698-7702. [CrossRef] [PubMed]

35. Ellard, S.; Beards, F.; Allen, L.; Shepherd, M.; Ballantyne, E.; Harvey, R.; Hattersley, A.T. A high prevalence of glucokinase mutations in gestational diabetic subjects selected by clinical criteria. Diabetologia 2000, 43, 250-253. [CrossRef] [PubMed]

36. Pruhova, S.; Dusatkova, P.; Sumnik, Z.; Kolouskova, S.; Pedersen, O.; Hansen, T.; Cinek, O.; Lebl, J. Glucokinase diabetes in 103 families from a country-based study in the Czech Republic: Geographically restricted distribution of two prevalent GCK mutations. Pediatr. Diabetes 2010, 11, 529-535. [CrossRef]

37. Aloi, C.; Salina, A.; Minuto, N.; Tallone, R.; Lugani, F.; Mascagni, A.; Mazza, O.; Cassanello, M.; Maghnie, M.; d'Annunzio, G. Glucokinase mutations in pediatric patients with impaired fasting glucose. Acta Diabetol. 2017, 54, 913-923. [CrossRef]

38. George, D.C.; Chakraborty, C.; Haneef, S.A.; Nagasundaram, N.; Chen, L.; Zhu, H. Evolution- and structure-based computational strategy reveals the impact of deleterious missense mutations on MODY 2 (maturity-onset diabetes of the young, type 2). Theranostics 2014, 4, 366-385. [CrossRef] 
39. Cho, J.; Horikawa, Y.; Enya, M.; Takeda, J.; Imai, Y.; Imai, Y.; Handa, H.; Imai, T. L-Arginine prevents cereblon-mediated ubiquitination of glucokinase and stimulates glucose-6-phosphate production in pancreatic $\beta$-cells. Commun. Biol. $2020,3,497$. [CrossRef]

40. Boj, S.F.; Parrizas, M.; Maestro, M.A.; Ferrer, J. A transcription factor regulatory circuit in differentiated pancreatic cells. Proc. Natl. Acad. Sci. USA 2001, 98, 14481-14486. [CrossRef]

41. Reznik, Y.; Dao, T.; Coutant, R.; Chiche, L.; Jeannot, E.; Clauin, S.; Rousselot, P.; Fabre, M.; Oberti, F.; Fatome, A.; et al. Hepatocyte nuclear factor-1 alpha gene inactivation: Cosegregation between liver adenomatosis and diabetes phenotypes in two maturity-onset diabetes of the young (MODY)3 families. J. Clin. Endocrinol. Metab. 2004, 89, 1476-1480. [CrossRef] [PubMed]

42. Simms, R.J.; Sayer, J.A.; Quinton, R.; Walker, M.; Ellard, S.; Goodship, T.H.J. Monogenic diabetes, renal dysplasia and hypopituitarism: A patient with a HNF1A mutation. QJM Int. J. Med. 2011, 104, 881-883. [CrossRef] [PubMed]

43. Fajans, S.S.; Bell, G.I. Phenotypic heterogeneity between different mutations of MODY subtypes and within MODY pedigrees. Diabetologia 2006, 49, 1106-1108. [CrossRef] [PubMed]

44. Colclough, K.; Bellanne-Chantelot, C.; Saint-Martin, C.; Flanagan, S.E.; Ellard, S. Mutations in the genes encoding the transcription factors hepatocyte nuclear factor 1 alpha and 4 alpha in maturity-onset diabetes of the young and hyperinsulinemic hypoglycemia. Hum. Mutat. 2013, 34, 669-685. [CrossRef]

45. Zhou, X.; Chen, C.; Yin, D.; Zhao, F.; Bao, Z.; Zhao, Y.; Wang, X.; Li, W.; Wang, T.; Jin, Y.; et al. A Variation in the ABCC8 Gene Is Associated with Type 2 Diabetes Mellitus and Repaglinide Efficacy in Chinese Type 2 Diabetes Mellitus Patients. Intern. Med. 2019, 58, 2341-2347. [CrossRef]

46. Vaxillaire, M.; Dechaume, A.; Busiah, K.; Cavé, H.; Pereira, S.; Scharfmann, R.; de Nanclares, G.P.; Castano, L.; Froguel, P.; Polak, M. SUR1-Neonatal Diabetes Study Group. New ABCC8 mutations in relapsing neonatal diabetes and clinical features. Diabetes 2007, 56, 1737-1741. [CrossRef]

47. Edghill, E.L.; Flanagan, S.E.; Ellard, S. Permanent neonatal diabetes due to activating mutations in ABCC8 and KCNJ11. Rev. Endocr. Metab. Disord. 2010, 11, 193-198. [CrossRef]

48. Calabria, A.C.; Li, C.; Gallagher, P.R.; Stanley, C.A.; De León, D.D. GLP-1 receptor antagonist exendin-(9-39) elevates fasting blood glucose levels in congenital hyperinsulinism owing to inactivating mutations in the ATP-sensitive K+ channel. Diabetes 2012, 61, 2585-2591. [CrossRef]

49. De Franco, E.; Saint-Martin, C.; Brusgaard, K.; Knight Johnson, A.E.; Aguilar-Bryan, L.; Bowman, P.; Arnoux, J.B.; Larsen, A.R.; Sanyoura, M.; Greeley, S.A.W.; et al. Update of variants identified in the pancreatic $\beta$-cell $\mathrm{K}_{\mathrm{ATP}}$ channel genes $K C N J 11$ and $A B C C 8$ in individuals with congenital hyperinsulinism and diabetes. Hum. Mutat. 2020, 41, 884-905. [CrossRef]

50. El-Khairi, R.; Vallier, L. The role of hepatocyte nuclear factor $1 \beta$ in disease and development. Diabetes Obes. Metab. 2016, 18, 23-32. [CrossRef]

51. Klimontov, V.V.; Bulumbaeva, D.M.; Koroleva, E.A.; Ovsyannikova, A.K.; Rymar, O.D.; Ivanoshchuk, D.E.; Shakhtshneider, E.V. Maturity-onset diabetes of the young due to HNF1B mutation: A case report. In Proceedings of the Systems Biology and Biomedicine, SBioMed-2018\Systems Biology (BGRS \SB-2018), Novosibirsk, Russia, 20-25 August 2018; p. 64, ISBN 9785-91291-040-1.

52. Weber, S.; Moriniere, V.; Knüppel, T.; Charbit, M.; Dusek, J.; Ghiggeri, G.M.; Jankauskiené, A.; Mir, S.; Montini, G.; Peco-Antic, A.; et al. Prevalence of mutations in renal developmental genes in children with renal hypodysplasia: Results of the ESCAPE study. J. Am. Soc. Nephrol. 2006, 17, 2864-2870. [CrossRef] [PubMed]

53. Karges, B.; Bergmann, C.; Scholl, K.; Heinze, E.; Rasche, F.M.; Zerres, K.; Debatin, K.M.; Wabitsch, M.; Karges, W. Digenic Inheritance of Hepatocyte Nuclear Factor $-1 \alpha$ and $-1 \beta$ With Maturity-Onset Diabetes of the Young, Polycystic Thyroid, and Urogenital Malformations. Diabetes Care 2007, 30, 1613-1614. [CrossRef] [PubMed]

54. Urrutia, I.; Martínez, R.; Rica, I.; Martínez de LaPiscina, I.; García-Castaño, A.; Aguayo, A.; Calvo, B.; Castaño, L. Spanish Pediatric Diabetes Collaborative Group. Negative autoimmunity in a Spanish pediatric cohort suspected of type 1 diabetes, could it be monogenic diabetes? PLoS ONE 2019, 14, e0220634. [CrossRef]

55. Dedov, I.I.; Zubkova, N.A.; Arbatskaya, N.Y.; Akopova, A.G.; Tyul'pakov, A.N. MODY2: Clinical and molecular genetic characteristics of 13 cases of the disease. The first description of MODY in Russia. Probl. Endokrinol. 2009, 55, 3-7. [CrossRef] [PubMed]

56. Glotov, O.S.; Serebryakova, E.A.; Turkunova, M.E.; Efimova, O.A.; Glotov, A.S.; Barbitoff, Y.A.; Nasykhova, Y.A.; Predeus, A.V.; Polev, D.E.; Fedyakov, M.A.; et al. Whole-exome sequencing in Russian children with non-type 1 diabetes mellitus reveals a wide spectrum of genetic variants in MODY-related and unrelated genes. Mol. Med. Rep. 2019, 20, 4905-4914. [CrossRef]

57. GoodSmith, M.S.; Skandari, M.R.; Huang, E.S.; Naylor, R.N. The Impact of Biomarker Screening and Cascade Genetic Testing on the Cost-Effectiveness of MODY Genetic Testing. Diabetes Care 2019, 42, 2247-2255. [CrossRef] 